\title{
Effect of pretreatment on the performance of metal-contaminated fluid catalytic cracking (FCC) catalysts
}

\author{
Oguz Bayraktar ${ }^{a}, *$ Edwin L. Kugler ${ }^{b}$ \\ ${ }^{a}$ Department of Chemical Engineering, Izmir Institute of Technology, Gülbahçe Köyü, 35437 Urla-Izmir, Turkey \\ ${ }^{\mathrm{b}}$ Department of Chemical Engineering, CEMR, P.O. Box 6102, West Virginia University, Morgantown, WV 26506-6102, USA
}

Received 30 June 2003; received in revised form 8 October 2003; accepted 9 October 2003

\begin{abstract}
Effects of both hydrogen and methane pretreatment on the performance of metal-contaminated equilibrium fluid catalytic cracking (FCC) catalysts from a refinery were investigated. Both hydrogen and methane pretreatment at $700^{\circ} \mathrm{C}$ were proven to be advantageous since the yields of hydrogen and coke from sour imported gas oil (SIHGO) cracking decrease while light cycle oil (LCO) and gasoline yields increase. The catalysts pretreated with hydrogen have shown slightly better improvement than the catalysts pretreated with methane. The decrease in the yields of hydrogen and coke was attributed to decrease in the dehydrogenation activity of vanadium oxides, which are present at high concentrations on the equilibrium FCC catalysts. This decrease in dehydrogenation activity after the pretreatment was also confirmed by low hydrogen-to-methane ratio. It was found that reduced vanadium has lower dehydrogenation activity since it produces less coke and hydrogen compared to oxidized vanadium.

Hydrogen transfer reactions were evaluated by measuring $\mathrm{C}_{4}$ paraffin-to- $\mathrm{C}_{4}$ olefin ratios. Hydrogen transfer reactions decreased with increasing metal concentration. Both hydrogen and methane pretreatment caused the hydrogen transfer reactions to increase. Improved hydrogen transfer reactions caused an increase in the gasoline range products.
\end{abstract}

(C) 2003 Elsevier B.V. All rights reserved.

Keywords: Fluidized catalytic cracking catalysts; Vanadium oxides; Pretreatment; Hydrogen; Methane

\section{Introduction}

The fluid catalytic cracking (FCC) process is used for the conversion of relatively high-boiling hydrocarbons to lighter hydrocarbons boiling in the heating oil and gasoline (or lighter) range. To take full advantage of marketing opportunities, some refiners are blending residual with their gas oil feed stock $[1,2]$. In fact, the majority of cracking expansions have been designed to process residual oil. In response to the demand for catalyst for these crackers, manufacturers are designing and developing specific catalyst that have good hydrothermal stability, high metal tolerance, and good bottoms upgrading [3].

A common problem in FCC processing is the gradual deterioration of the catalyst due to the deposition of metal

\footnotetext{
* Corresponding author. Tel.: +90-232-498-6287; fax: +90-232-498-6355.

E-mail address: oguzbayraktar@iyte.edu.tr (O. Bayraktar).
}

contaminants, such as nickel, vanadium, and iron as a non-volatile compound on the cracking catalyst. These metals increases the hydrogen and coke yields at the expense of gasoline [4,5]. These deposited metal contaminants are not removed during conventional catalyst regeneration operations during which coke deposits on the catalyst are converted to $\mathrm{CO}$ and $\mathrm{CO}_{2}$. While it would be ideal to remove these contaminants, such procedures are usually quite elaborate and expensive. A simpler approach is to neutralize or specify the metals present on the catalyst [6]. Such a procedure does not necessarily restore the full clean catalyst activity (since metals may still block a percentage of the catalyst sites), but is quite helpful in lowering hydrogen gas production which can overload gas compressors and in reducing coke on the catalyst resulting from active metal influences.

In this paper, we will investigate the effects of pretreatment with hydrogen or methane as a reducing gas on the performance of commercial, metals-contaminated, equilibrium FCC catalysts. 


\section{Experimental}

\subsection{FCC catalysts and catalyst pretreatment}

Commercial equilibrium FCC catalysts supplied by Ashland Inc. were used in cracking experiments. They are named ECat-LOW, ECat-INT, and ECat-HIGH based on their contaminant-metals concentration. Additional information on these catalysts is given in the previous paper [7]. Mainly, ECat-LOW contains $300 \mathrm{mg} \mathrm{kg}^{-1}$ nickel and $700 \mathrm{mg} \mathrm{kg}^{-1}$ vanadium; ECat-INT contains $900 \mathrm{mg} \mathrm{kg}^{-1}$ nickel and $1700 \mathrm{mg} \mathrm{kg}^{-1}$ vanadium; ECat-HIGH contains $2600 \mathrm{mg} \mathrm{kg}^{-1}$ nickel and $6700 \mathrm{mg} \mathrm{kg}^{-1}$ vanadium.

Commercial equilibrium FCC catalysts were either calcined or pretreated before they were used in catalytic cracking reaction. Calcination was performed at $550{ }^{\circ} \mathrm{C}$ for $6 \mathrm{~h}$ to make sure that no coke deposits exists before cracking reactions. Two types of pretreatment using hydrogen and methane were performed in this study. These pretreatments were carried out at $700{ }^{\circ} \mathrm{C}$ for approximately $6 \mathrm{~h}$ by using $8 \%$ hydrogen in argon or $8 \%$ methane in helium with a quartz reactor in the microactivity test (MAT) unit. They were aimed to reduce the oxidation state of metal contaminants on the catalyst. All of the gas mixtures were obtained from Matheson and used as received.

\subsection{Cracking experiments}

Microactivity test measurements of catalyst activity were performed according to the procedures of ASTM D-3907 using SIHGO (Davison Chemical Co.) feed. The MAT unit was manufactured by Industrial Automated Systems (Parlin, New Jersey). The microactivity test unit consists of a furnace for maintaining constant cracking temperature $\left(500^{\circ} \mathrm{C}\right)$, a syringe pump whose speed can be varied to inject the cracking feed, a liquid product receiver, and a gas collection vessel. Liquid products were condensed at the exit of the reactor by using ice-water mixture. Product gases were collected by downward displacement of water. To achieve different conversions the reaction severity was varied by changing the catalyst-to-oil ratio $(\mathrm{C} / \mathrm{O})$ where $\mathrm{C} / \mathrm{O}$ ratio is defined as the amount of catalyst divided by the total amount of feed. This ratio was changed by changing the amount of feed while keeping the catalyst amount constant at $5 \mathrm{~g}$. The $\mathrm{C} / \mathrm{O}$ ratios of 3,5 , and 8 were used in the cracking experiments.

\subsection{Analysis of products}

The gas sample was immediately analyzed using a VARIAN 3600 gas chromatograph. $\mathrm{H}_{2}, \mathrm{C}_{1}, \mathrm{C}_{2}, \mathrm{C}_{3}, \mathrm{C}_{4}$, and $\mathrm{C}_{5}{ }^{+}$ lump were determined quantitatively. This GC has two types of detectors, FID and TCD. A porous layer open tubular (PLOT) GS-alumina column and a HAYESEP-DIP 60/80 column were used to accomplish the separation. The PLOT alumina column identifies $\mathrm{C}_{1}-\mathrm{C}_{5}$ 's. The PLOT column was connected to the FID for direct quantification of hydrocar- bon products. The HAYESEP column was used in series with a TCD to identify and measure hydrogen. Initially, a calibration standard of $1 \%$ hydrogen and $0.98 \%$ iso-butane in nitrogen was run. Since retention time and concentration of these two gases were known, quantitative analysis of the gas products obtained from MAT analysis was performed. This allowed the determination of the amount (weight) of gaseous products obtained from each run, which was used to calculate the mass balance over the entire unit.

The liquid products, after weighting, were dissolved in $\mathrm{CS}_{2}$ solvent and analyzed by GC simulated distillation. D2887 simulated distillation method was used to determine the percentage of the liquid products boiling in the range of gasoline (IBP-421 F), light cycle oil, (LCO) (421-640 F), and heavy cycle oil (HCO) (640 F and above). A Supelco Petrocol B packed column installed in a VARIAN 3400 GC was used. Using this method, the conversion as defined by ASTM 3907 was calculated.

Amount of coke on the spent catalyst was determined gravimetrically by burning it off in a muffle furnace.

\section{Results and discussion}

\subsection{Calcined catalysts}

Results from cracking reactions are summarized in Table 1. These cracking reactions were at three different catalyst-to-oil ratios (3, 5, and 8). MAT conversion decreases with increasing metals on the catalyst for a given catalyst-to-oil ratio. For example, MAT conversion decreases from $59-46 \%$ at $\mathrm{C} / \mathrm{O}$ ratio of 3 with increasing metal concentration on the catalysts. Conversion increases with increasing $\mathrm{C} / \mathrm{O}$ ratio for both ECat-LOW and ECat-HIGH. The lower MAT conversions for ECat-HIGH compared to ECat-LOW are due to the negative impact of high metal concentration on catalyst activity. The aging of these two catalysts are also different. The lower surface area of ECat-HIGH is consistent with it being older than ECat-LOW. The higher the metal contaminants level, especially nickel, the older the equilibrium catalyst. Because of the nature of FCC unit operation a part of the catalyst inventory is replaced with fresh catalyst periodically (normally once a day). This action causes a distribution of properties reflecting the age distribution in any equilibrium sample. If the feeds and the catalysts are the same, a younger catalyst will have a higher surface area and contain less nickel.

The changes of gas, gasoline, and coke yields at different MAT conversions for calcined ECat-LOW and ECatHIGH are tabulated in Table 1. As expected, while the yields of LCO and HCO decrease yields for gas, gasoline, and coke increase with increasing MAT conversion. Performing cracking reactions at different catalyst-to-oil ratios allowed us to change the conversions. The catalyst-tooil ratios of 3,5 , and 8 were obtained by injecting different amounts of cracking feed while keeping the 
Table 1

Yeilds (wt.\%) from cracking reactions of SIHGO feed at C/O ratio of 3, 5, and 8 under different pretreatment conditions

\begin{tabular}{|c|c|c|c|c|c|c|c|c|c|c|c|c|c|c|}
\hline & \multicolumn{6}{|c|}{ Calcined } & \multicolumn{4}{|c|}{$\mathrm{H}_{2}$ pretreated } & \multicolumn{4}{|c|}{$\mathrm{CH}_{4}$ pretreated } \\
\hline & \multicolumn{3}{|c|}{ ECat-LOW } & \multicolumn{3}{|c|}{ ECat-HIGH } & \multicolumn{2}{|c|}{ ECat-LOW } & \multicolumn{2}{|c|}{ ECat-HIGH } & \multicolumn{2}{|c|}{ ECat-LOW } & \multicolumn{2}{|c|}{ ECat-HIGH } \\
\hline & 3 & 5 & 8 & 3 & 5 & 8 & 3 & 5 & 3 & 5 & 3 & 5 & 3 & 5 \\
\hline $\mathrm{C}_{1}+\mathrm{C}_{2}$ & 0.78 & 1.13 & 1.47 & 0.56 & 0.88 & 0.98 & 0.79 & 0.98 & 0.48 & 0.62 & 0.65 & 1.01 & 0.43 & 0.62 \\
\hline $\mathrm{C}_{3}+\mathrm{C}_{4}$ & 9.82 & 12.02 & 13.76 & 7.18 & 9.04 & 11.09 & 10.13 & 10.48 & 6.64 & 7.16 & 9.12 & 10.49 & 6.14 & 6.79 \\
\hline Gasoline $(<421 \mathrm{~F})$ & 43.53 & 46.55 & 53.97 & 32.57 & 37.28 & 43.24 & 40.38 & 47.65 & 33.51 & 40.22 & 40.61 & 46.21 & 31.67 & 38.33 \\
\hline LCO (421-640 F) & 26.72 & 22.89 & 17.31 & 30.10 & 26.69 & 23.11 & 28.12 & 23.90 & 32.37 & 30.55 & 28.66 & 23.31 & 31.46 & 29.26 \\
\hline $\mathrm{HCO}(>640 \mathrm{~F})$ & 14.54 & 8.88 & 1.94 & 23.85 & 17.43 & 9.65 & 15.34 & 9.76 & 22.78 & 15.84 & 15.43 & 10.66 & 25.81 & 19.00 \\
\hline Coke & 5.11 & 8.46 & 11.32 & 5.45 & 8.31 & 11.54 & 5.20 & 7.16 & 4.11 & 5.43 & 5.46 & 8.24 & 4.33 & 5.79 \\
\hline $\mathrm{H}_{2}$ & 0.07 & 0.09 & 0.11 & 0.28 & 0.38 & 0.38 & 0.05 & 0.06 & 0.12 & 0.18 & 0.07 & 0.08 & 0.15 & 0.21 \\
\hline $\mathrm{H}_{2} / \mathrm{CH}_{4}$ & 1.66 & 1.82 & 2.2 & 7.48 & 8.36 & 8.90 & 1.36 & 1.57 & 5.66 & 5.77 & 1.50 & 1.70 & 6.20 & 6.53 \\
\hline $\mathrm{C}_{4}$ paraffin/ $\mathrm{C}_{4}$ olefin & 2.25 & 2.61 & 3.2 & 1.04 & 1.29 & 1.53 & 1.85 & 2.76 & 1.08 & 1.36 & 1.78 & 2.75 & 1.15 & 1.40 \\
\hline MAT conversion & 59.31 & 68.21 & 80.63 & 46.05 & 55.89 & 67.24 & 56.55 & 66.34 & 44.85 & 53.61 & 55.91 & 66.03 & 42.75 & 51.74 \\
\hline
\end{tabular}

catalyst- amount constant at $5 \mathrm{~g}$. It is quite difficult to obtain exactly the desired catalyst-to-oil-ratios and conversion values. Therefore, we have used gas, gasoline, and coke yields for each corresponding conversion value regardless of the exact catalyst-to-oil ratio. Table 2 was generated by interpolating the yield data given in Table 1 for a constant MAT conversion of $60 \%$. Table 2 compares the yields of gas, gasoline, coke, LCO, and HCO between ECat-LOW and ECat-HIGH at a constant MAT conversion of $60 \%$. As seen from Table 2, for calcined catalysts coke yield increases while gasoline yield decreases with increasing metals level. LCO and HCO yields do not change significantly.

\subsection{Pretreatment with hydrogen or methane}

Table 1 summarizes the effect of conversion on the yields of gas, gasoline, LCO, HCO, and coke for both ECat-LOW and ECat-HIGH pretreated with either hydrogen or methane. The cracking experiments were performed at two different $\mathrm{C} / \mathrm{O}$ ratios (3 and 5). Both hydrogen and methane pretreatments cause the MAT conversion at the same $\mathrm{C} / \mathrm{O}$ ratios to shift slightly lower values compared to the conversions for calcined ECat-LOW and calcined ECat-HIGH.

Table 2 compares the yields of gas, gasoline, coke, LCO, and $\mathrm{HCO}$ before and after hydrogen or methane pretreatment of ECat-LOW at a constant MAT conversion of $60 \%$. As seen from Table 2, effect of pretreatments on the yields

Table 2

Comparison of yields at $60 \%$ MAT conversion for both calcined and pretreated equilibrium FCC catalysts

\begin{tabular}{lllllll}
\hline Catalyst & Pretreatment & \multicolumn{5}{l}{ Yields } \\
\cline { 3 - 7 } & & Gas & Gasoline & Coke & LCO & HCO \\
\hline ECat-LOW & Calcined & 11.06 & 43.36 & 5.64 & 26.43 & 14.00 \\
& $\mathrm{H}_{2}$ pretreatment & 11.16 & 42.94 & 5.91 & 26.60 & 13.33 \\
& $\mathrm{CH}_{4}$ pretreatment & 10.54 & 42.88 & 6.57 & 26.52 & 13.52 \\
ECat-HIGH & Calcined & 11.01 & 39.52 & 9.48 & 25.43 & 14.53 \\
& $\mathrm{H}_{2}$ pretreatment & 8.49 & 45.12 & 6.39 & 29.22 & 10.78 \\
& $\mathrm{CH}_{4}$ pretreatment & 8.45 & 44.45 & 7.13 & 27.24 & 12.74 \\
\hline
\end{tabular}

of gas, gasoline, and coke for ECat-LOW was not significant. However, for ECat-HIGH pretreated with either hydrogen or methane gasoline and LCO yields increase while the gas, coke, and HCO yields decrease compared to the calcined ECat-HIGH. This result is not surprising since there is not much contaminant metals on ECat-LOW compared to ECat-HIGH catalyst to be able to observe the possible effects of pretreatment on the catalyst performance.

\subsection{Hydrogen production in the presence of contaminant metals}

$\mathrm{H}_{2}$ yields from MAT experiments have usually been reported by using hydrogen-to-methane $\left(\mathrm{H}_{2} / \mathrm{CH}_{4}\right)$ molar ratio. Hydrogen production was found to be very sensitive to catalyst metal contamination [8]. At low catalyst metals level $\left(<1000 \mathrm{mg} \mathrm{kg}^{-1} \mathrm{Ni}+\mathrm{V}\right) \mathrm{H}_{2} / \mathrm{CH}_{4}$ ratios of less than 1.0 were found to be typical. At metals level of $1000-1500 \mathrm{mg} \mathrm{kg}^{-1}$, which is the normal level for many FCC units, $\mathrm{H}_{2} / \mathrm{CH}_{4}$ ratios of $1-2$ were found to be typical. For the case of severe metals contamination when $\mathrm{Ni}+\mathrm{V}$ levels have risen above $5000 \mathrm{mg} \mathrm{kg}^{-1}, \mathrm{H}_{2} / \mathrm{CH}_{4}$ ratios of 10 or higher would be typical. As seen from Fig. $1, \mathrm{H}_{2} / \mathrm{CH}_{4}$ molar ratio is very sensitive to catalyst metal contamination. When the metals on the catalyst increase, this ratio also increases. This ratio increases with increasing MAT conversions for all the equilibrium catalysts as seen from Fig. 1. In this study, the $\mathrm{H}_{2} / \mathrm{CH}_{4}$ molar ratios were found to be $1.6,3.5$, and 8.5 for ECat-LOW $\left(1000 \mathrm{~m} \mathrm{~kg} \mathrm{k}^{-1}\right)$, ECat-INT $\left(2600 \mathrm{mg} \mathrm{kg}^{-1}\right)$ and ECat-HIGH (9300 $\mathrm{m} \mathrm{kg}^{-1}$ ), respectively, at a constant MAT conversion of $60 \%$. These values are the clear indication of the increase in hydrogen yield with increasing metals concentration on the catalysts. Pretreatment did not have any significant effect on hydrogen-to-methane ratio for ECat-LOW. Hydrogen-to-methane ratio slightly decreases with both hydrogen and methane pretreatment. As shown in Fig. 1, for ECat-HIGH hydrogen-to-methane ratio decreases with both pretreatments. This indicates that after pretreatment metals on the catalyst lose their activities to produce hydrogen by 


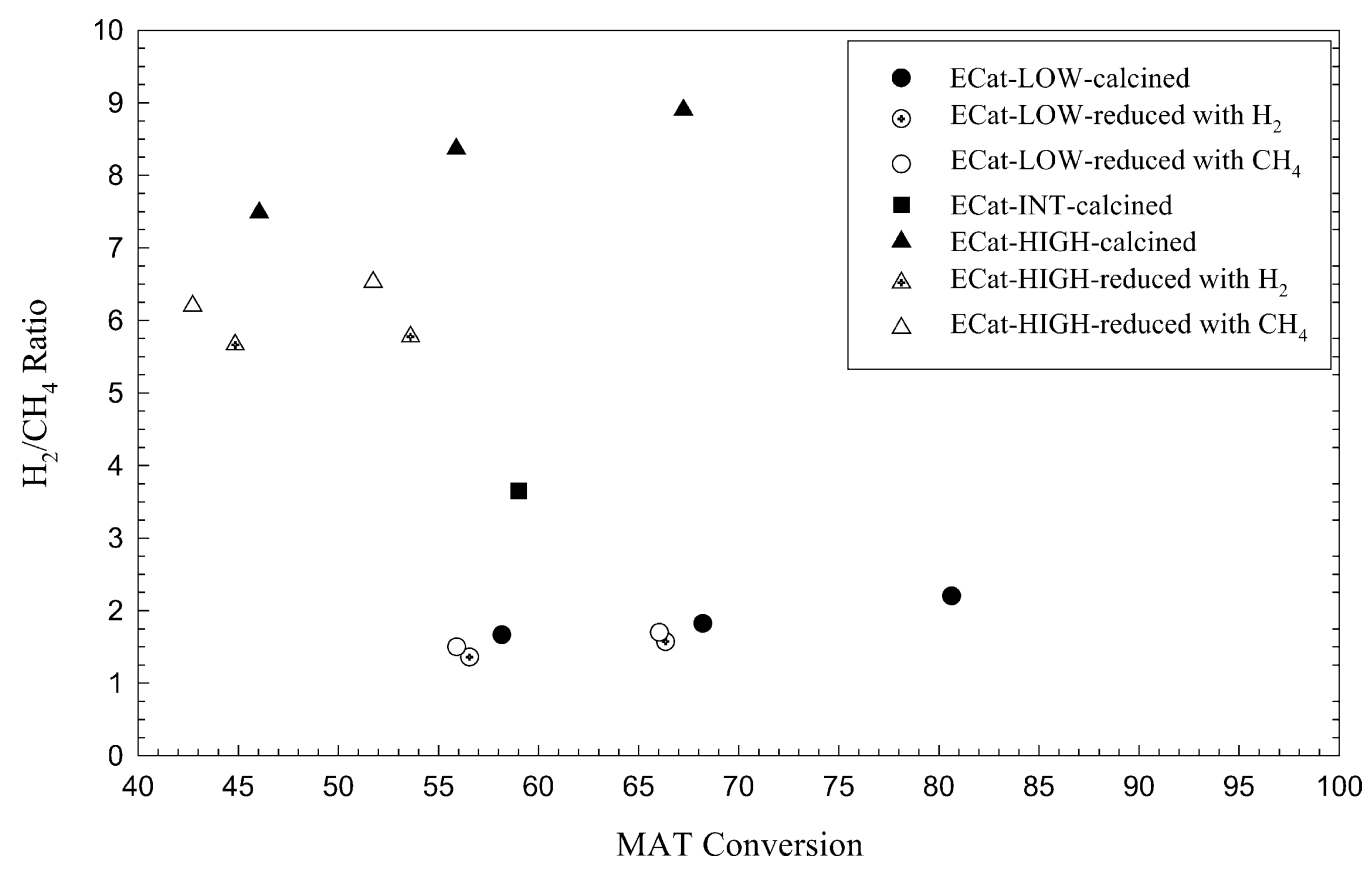

Fig. 1. Comparison of hydrogen-to-methane ratios for calcined or pretreated equilibrium FCC catalysts at different MAT conversions.

dehydrogenation reactions. We clearly see this net effect in ECat-HIGH, since this is the catalyst with highest metal concentration on it.

\subsection{Hydrogen transfer reactions}

$\mathrm{C}_{4}$ paraffin-to- $\mathrm{C}_{4}$ olefin ratio is usually used as an indication of the hydrogen transfer reactions. If this ratio is high, it means hydrogen transfer reactions play an important role. Fig. 2 compares the $\mathrm{C}_{4}$ paraffin-to- $\mathrm{C}_{4}$ olefin ratio between ECat-LOW and ECat-HIGH to determine the effect of met- als level on hydrogen transfer reactions. $\mathrm{C}_{4}$ paraffin-to- $\mathrm{C}_{4}$ olefin ratio, indicating hydrogen transfer reactions, increases with increasing MAT conversions for both calcined catalysts. However, at constant MAT conversion this ratio for calcined ECat-HIGH was always found to be less than that observed for calcined ECat-LOW. This indicates that the hydrogen transfer reactions are reduced in the presence of metal contaminants. Therefore, more olefins are produced in the case of ECat-HIGH compared to ECat-LOW. The hydrogen transfer reactions are expected to be less significant for ECat-HIGH compared to ECat-LOW. This poor

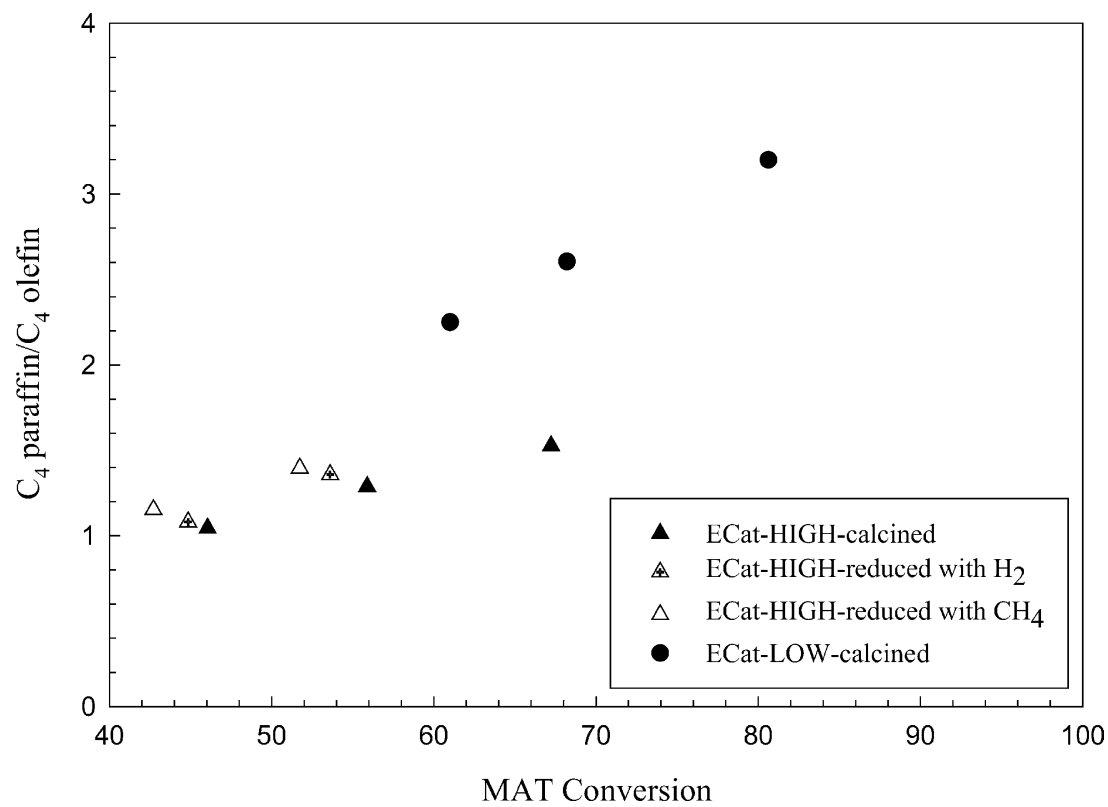

Fig. 2. Comparisons of $\mathrm{C}_{4}$ paraffin-to- $\mathrm{C}_{4}$ olefin ratios with respect to MAT conversions for calcined or pretreated equilibrium FCC catalysts. 
hydrogen transfer for ECat-HIGH leads to overcracking of primary products to secondary products of smaller molecular weight and causes coke formation. When hydrogen transfer reactions increase the MAT conversion increases. Fig. 2 also shows the $\mathrm{C}_{4}$ paraffin-to- $\mathrm{C}_{4}$ olefin ratios for pretreated ECat-LOW and ECat-HIGH catalysts at different MAT conversions. This ratio increases with increasing conversions. However, for ECat-LOW pretreatments do not affect this ratio (i.e., hydrogen transfer reactions) very much. The situation was completely different for ECat-HIGH. This ratio increases slightly with both hydrogen and methane pretreatments. Hydrogen transfer reactions increases the gasoline range products by terminating carbocations and saturating olefins before they can undergo further cracking [9]. The improved hydrogen transfer reactions with pretreatment for ECat-HIGH may be the reason for the increase in gasoline yield and decrease in gas and coke yields.

Lee [10] studied catalytic cracking in the presence of hydrogen. He found that presence of hydrogen during the catalytic cracking shifted cracking products toward the heavier end, i.e., lower conversion; higher selectivities to gasoline, light cycle oil and heavy cycle oil; and lower coke yield [10]. The improvements in gasoline yield were found to be more significant with a relatively high-metal catalyst than those with a low-metal catalyst. Part of the improvements in performance of metal contaminated catalyst used for the catalytic cracking in the presence of hydrogen was attributed to metal reduction similar to hydrogen pretreatment [10].

The improvement of catalyst performance with hydrogen or methane pretreatments can be explained by the oxidation states of metals such as vanadium and nickel on these equilibrium catalysts. Under FCC conditions, nickel is present in either the +2 or zero valance state. It is known that nickel at zero valance state is active for promoting dehydrogenation reactions causing coke and hydrogen production [3]. Nickel in +2 valance on a surface like alumina forms nickel aluminate $[11,12]$. In the previous paper [7], it has been shown that after several reduction-oxidation cycles nickel forms nickel aluminate type compounds which appear as a high temperature peak in the temperature-programmed reduction (TPR) profile. Cadet et al. [11] have shown that nickel aluminate can also promote dehydrogenation reactions, although its dehydrogenation rate was found to be less than the rate for nickel metal.

Vanadium can also exist in several oxidation states between +3 and +5 . However, vanadium does not exist at zero valance state under FCC conditions. It is known that vanadium has a dehydrogenation activity and this dehydrogenation activity is closely related to its oxidation state [3,12-14]. It was reported that oxidized vanadium produces more coke and hydrogen compared to reduced vanadium, indicating its high dehydrogenation activity [15]. In equilibrium, catalysts used for this study vanadium exists at its +5 state in large quantities. Oxidized vanadium produces olefins from paraffins by dehydrogenation reactions while reducing itself into +4 and +3 oxidation states [15]. Dehydrogenation reactions catalyzed by oxidized vanadium may be the reason for getting high olefin yield with highly contaminated equilibrium catalyst. As seen from Fig. 2, high light olefin yield in our results is also reflected by the relatively low $\mathrm{C}_{4}$ paraffin-to- $\mathrm{C}_{4}$ olefin ratios and high hydrogen-to-methane ratios for highly contaminated ECat-HIGH catalyst compared to relatively less contaminated ECat-LOW catalyst. Wallenstein et al. [16] also reported higher olefin yields for the metallated catalysts. In their study, after catalysts were impregnated with vanadium and nickel catalysts were exposed to 30 cycles of oxidizing and reducing atmosphere at $788^{\circ} \mathrm{C}$. The higher olefin yields for metallated catalysts compared to non-metallated catalyst was attributed to the dehydrogenation activity of vanadium and nickel [16]. Both hydrogen and methane used as pretreatment gases in this study have the ability to reduce metal oxides on the catalysts. Once the vanadium oxides, which are present in large quantities, are reduced during the catalyst pretreatment procedure, their catalytic activity to promote dehydrogenation reactions to form olefin from paraffins decreases significantly. This is confirmed by obtaining relatively high $\mathrm{C}_{4}$ paraffin-to- $\mathrm{C}_{4}$ olefin ratios and low hydrogen-to-methane ratios after catalysts are pretreated with either hydrogen or methane.

As reported in the previous study [7], the TPR spectra of highly contaminated equilibrium catalyst, ECat-HIGH, before and after ex situ hydrogen pretreatment allow us to understand the effect of pretreatment on the observed catalyst activity. Normally, A temperature-programmed reduction study of equilibrium FCC catalysts has shown three hydrogen-consumption peaks associated with contaminant metals is produced by the reduction of several components in the catalyst. Highly dispersed vanadium contributes to the low-temperature peak, located near $510^{\circ} \mathrm{C}$. A high-temperature peak, located near $800^{\circ} \mathrm{C}$, is produced by reduction of nickel-aluminate type compounds. An intermediate-temperature peak, located near $690^{\circ} \mathrm{C}$, appears to be related to some form of vanadium compound [7].

After pretreating the catalyst with hydrogen at $500^{\circ} \mathrm{C}$, most of the metal oxides on the catalyst represented by the first peak around $510^{\circ} \mathrm{C}$ in TPR spectrum are reduced. Our activity measurements have shown that there was no significant effect of pretreatment with hydrogen at $500^{\circ} \mathrm{C}$ on the activity of ECat-HIGH. After pretreating the catalyst with hydrogen at $700^{\circ} \mathrm{C}$ in addition to the metal oxides represented by the first peak at $510^{\circ} \mathrm{C}$ in TPR spectrum, metal oxides represented by the intermediate peak located at $690^{\circ} \mathrm{C}$ are also reduced. Since the catalyst pretreated with hydrogen at $700^{\circ} \mathrm{C}$ has shown improvement in its activity, the metal oxides, possibly the vanadium oxides, reduced at around $690^{\circ} \mathrm{C}$ in TPR spectrum, must be highly active for the dehydrogenation reactions. This also explains why the US patent suggests pretreatment temperatures above $650^{\circ} \mathrm{C}$, but not $500^{\circ} \mathrm{C}[6]$. 


\section{Conclusions}

We have shown that pretreatment with hydrogen or methane has significant effects on the performance of metal-contaminated equilibrium FCC catalysts. The yields of hydrogen and coke decreased with pretreatments while the gasoline yield increased. The improvement with pretreatment was found to be more significant with a relatively high metal catalyst than those with a low metal catalyst. C4 paraffin-to-C4 olefin ratio, which is a good indicator of hydrogen transfer reactions, decreased with increasing metal concentration on the catalyst. Pretreatment caused the hydrogen transfer reactions to increase. Improved hydrogen transfer reactions caused gasoline range products to increase by terminating carbocations and saturating olefins before they can undergo further cracking. Decrease in hydrogen and coke yields with pretreatment was explained by the reduction of the oxidation state of the vanadium, which is present at high levels on the equilibrium catalysts. It was found that reduced vanadium produced less coke and hydrogen compared to oxidized vanadium, indicating its low dehydrogenation activity.

\section{Acknowledgements}

Support from the Turkish Ministry of National Education and the West Virginia University Department of Chemical Engineering is gratefully acknowledged. We acknowledge Mr. Howard Moore, Ashland Marathon LLC, for his helpful discussions and for providing the equilibrium FCC catalyst samples used in this study.

\section{References}

[1] J.W. Gall, R.H. Nielsen, D.L. McKay, N.W., in: Mitchell, National Petroleum Refiners Association Annual Meeting, San Antonia, TX, Paper AM-82-50, 1982.

[2] A.K. Logwinuk, J.R. Murphy, in: National Petroleum Refiners Association Annual Meeting, San Antonia, TX, Paper AM-81-29, 1981.

[3] G.M. Woltermann, G. Dodwell, B. Lerner, in: National Petroleum Refiners Association Annual Meeting, San Antonia, TX, Paper AM-96-46, 1996.

[4] R.N. Cimbalo, R.L. Foster, S.J. Wachtel, Oil Gas J. 70 (1972) 112.

[5] E.T. Habib, H. Owen, P.W. Snyder, C.W. Streed, P.B. Venuto, Ind. Eng. Chem. Prod. Res. Dev. 16 (1977) 291.

[6] R. Bearden, G.F. Stuntz, US Patent 4409093 and 4372840 (1983), to Exxon Research and Engineering Co.

[7] O. Bayraktar, E.L. Kugler, Temperature-programmed reduction of metal-contaminated fluid catalytic cracking (FCC) catalysts, Appl. Catal., in press.

[8] P.B. Venuto, E.T. Habib, Fluid Catalytic Cracking with Zeolite Catalysts, Marcel-Dekker Inc., New York, 1979.

[9] B.C. Gates, J.R. Katzer, G.C.A. Schuit, Chemistry of Catalytic Processes, McGraw-Hill Book Company, 1979.

[10] F.M. Lee, Ind. Eng. Chem. Res. 28 (1989) 920.

[11] V. Cadet, F. Raatz, J. Lynch, C. Marcilly, Appl. Catal. 68 (1991) 263.

[12] W.C. Cheng, M.V. Juskels, W. Suárez, Appl. Catal. 103 (1993) 87.

[13] L.T. Boock, T.F. Petti, J.A. Rudesill, ACS Symp. Ser. 634 (1996) 171

[14] J.A. Rudesill, A.W. Peters, in M.L. Occelli, P. O'Connor (Eds.), Fluid Cracking Catalysts, Marcel-Decker, New York, 1999, p. 71 .

[15] L.T. Boock, T.F. Petti, J.A. Rudesill, A. John, in: Proceedings of the 210th National Meeting of the American Chemical Society, Chicago, IL, 1995, p. 421.

[16] D. Wallenstein, B. Kanz, A. Haas, Appl. Catal. 192 (2000) 105. 